\title{
Pervaporation Separation of Water-Isopropanol Mixtures Using ZSM-5 Zeolite Incorporated Poly(vinyl alcohol) Membranes
}

\author{
A. A. Kittur, ${ }^{1}$ M. Y. Kariduraganavar, ${ }^{1}$ U. S. Toti $^{1}{ }^{1}$ K. Ramesh $^{2}{ }^{2}$ T. M. Aminabhavi ${ }^{1}$ \\ ${ }^{1}$ Center of Excellence in Polymer Science, Karnatak University, Dharwad 580003, India \\ ${ }^{2}$ Department of Physics, Indian Institute of Science, Bangalore 560012, India
}

\begin{abstract}
A solution technique was employed to prepare ZSM-5 zeolite incorporated poly(vinyl alcohol) (PVA) membranes for the pervaporation separation of water-isopropanol mixtures. The membranes were characterized by Fourier transform infrared spectroscopy and differential scanning calorimeter. Glass transition temperatures of the membranes varied from 102 to $110^{\circ} \mathrm{C}$, with increasing zeolite content of the membrane. The effect of zeolite loading and feed composition on pervaporation performance of the membranes was analyzed. The membrane containing 6 mass $\%$ of zeolite gave the highest separation selectivity of 216 for 10 mass $\%$ of water containing feed mixture at $30^{\circ} \mathrm{C}$. Increase in water selectivity of the membrane was explained as due to a reduction in free volume by increasing zeolite content of the membrane. Separation selectivity and permeation flux
\end{abstract}

data are dependent on water composition of the feed mixture, but are comparatively less dependent on temperature. The hindrance of water permeation at higher composition of water in the feed mixture was explained as due to the formation of clusters of water molecules. The overall activation energy and preexponential factors were calculated using Arrhenius equation. Pervaporation data have also been explained on the basis of thermodynamic parameters calculated by using Arrhenius equation as well as relationship proposed by Ping et al.

Key words: separation techniques; membranes; zeolites; selectivity; activation energy

\section{INTRODUCTION}

Among the many aqueous-organic mixtures, separation of water from its mixture with isopropanol is a challenging task, because the system forms an azeotrope at 14.7 mass $\%$ of water; ${ }^{1}$ hence, its separation by conventional distillation is not feasible. In contrast, the pervaporation (PV) separation technique, being energy efficient, has been used widely to separate azeotropes even on a large scale. ${ }^{2-4} \mathrm{In} \mathrm{PV}$, the feed mixture is placed in contact with one side of the membrane while the vapor permeate is removed from the opposite side using a vacuum. The chemical potential gradient across the membrane is the driving force for the molecular transport. PV has several advantages over the conventional distillation, ${ }^{5}$ including reduced energy demand (only a fraction of the liquid is vaporized), and is eco-friendly in nature.

Correspondence to: M. Y. Kariduraganavar (mahadevappak@ yahoo.com).

Contract grant sponsor: Department of Science and Technology, New Delhi; contract grant number: SP/S1/H-31/ 2000
In PV separation studies of aqueous-organic mixtures, several types of membranes have been used including those of blends, composites, etc. In an earlier study, ${ }^{6}$ the blend membranes of sodium alginate with PVA have been employed to separate water-isopropanol mixtures. However, flux and selectivity of these membranes were not satisfactory. In an effort to increase the flux and selectivity of the membranes, many studies have been made to incorporate metal complexes and zeolites in the membranes. ${ }^{7-11}$ The zeoliteincorporated polymer membranes have received much attention recently in gas and PV separation studies. ${ }^{8,9}$ The incorporation of zeolite or porous fillers in dense membrane can improve the separation performance of the membranes ${ }^{7-11}$ due to combined effect of molecular sieving action, selective adsorption, and difference in diffusion rates. In addition, zeolites have high mechanical strength, good thermal and chemical stability, and thus, the membranes, when incorporated with these fillers, can be used over the wide range of operating conditions.

Silicalite and ZSM-5 zeolites having the MFI-type structures have been widely studied in membrane applications. ${ }^{12-15}$ Silicalite is a pure silica zeolite having straight channels interconnected by zigzag channels. The straight channels in ZSM-5 zeolite are elliptical, with an opening of $0.51 \times 0.57 \mathrm{~nm}$, and the 
sinusoidal channels are almost circular, with a diameter of $0.54 \mathrm{~nm} .{ }^{16}$ Poly(vinyl alcohol), the base polymer used in this study, has good film-forming properties, and is hydrophilic, which has been studied extensively as a PV membrane in various applications. PVA membranes are known to exhibit high swelling due to the presence of hydroxyl groups. To improve the membrane performance, it is necessary to maintain a balance between hydrophilicity by the addition of hydrophobic groups to achieve higher selectivity than the virgin PVA membrane. The present study aims at maintaining a proper balance between hydrophilicity and hydrophobicity of the membrane by incorporating different amount of hydrophobic ZSM-5 zeolite in PVA. The resulting membranes were tested for the PV separation of water-isopropanol mixtures at 30,40 , and $50^{\circ} \mathrm{C}$. Swelling experiments were performed to understand the effects of zeolite loading and feed compositions on the PV performance of the membranes. The overall activation energy of permeation and preexponential factors were calculated from the Arrhenius type relationship.

\section{EXPERIMENTAL}

\section{Materials}

Poly(vinyl alcohol) (A. R. Grade, M.W. 125,000), glutaraldehyde (GA), isopropanol (IPA), ZSM-5 zeolite, and hydrochloric acid were obtained from s.d. fine Chemicals, Mumbai, India. These were of reagent grade samples, which were used as received. Double distilled water was used throughout the research.

\section{Membrane preparation}

Poly(vinyl alcohol) (5 g) was dissolved in $100 \mathrm{~mL}$ of deareated-distilled water at $60^{\circ} \mathrm{C}$ with a constant stirring by purging a slow stream of nitrogen gas for about $30 \mathrm{~min}$. The solution was filtered, a known quantity of ZSM-5 zeolite was added, and it was dispersed with the help of sonicator for about $15 \mathrm{~min}$, and then kept stirring for overnight. Before casting the membrane, $1 \mathrm{~mL}$ of glutaraldehyde $(25 \%)$ and $20 \mathrm{~mL}$ of $0.1 \mathrm{~N} \mathrm{HCl}$ were added in situ for achieving the matrix crosslinking and stirred further for few minutes. Immediately, the solution was poured onto a clean glass plate to cast membranes of uniform thickness. The membranes were allowed to dry at room temperature for 2-3 days, and the completely dried membranes were peeled off. The amount of zeolite in the polymer was varied as 2,4 , and 6 mass $\%$, and the resulting membranes were designated as $\mathrm{M}-1, \mathrm{M}-2$, and M-3, respectively.

\section{Pervaporation experiments}

Pervaporation experiments have been carried out using an indigenously designed apparatus described
TABLE I

Pervaporation Flux and Separation Selectivity Data for Different Mass \% of Water in the Feed Mixture at $30^{\circ} \mathrm{C}$ for Different Membranes

\begin{tabular}{cccccrrr}
\hline \multirow{2}{*}{$\begin{array}{c}\text { Mass } \% \\
\text { water }\end{array}$} & \multicolumn{3}{c}{$J_{p} 10^{2}\left(\mathrm{~kg} / \mathrm{m}^{2} \mathrm{~h}\right)$} & & \multicolumn{3}{c}{$\alpha_{\text {sep }}$} \\
\cline { 8 - 9 } \cline { 7 - 8 } & M-1 & M-2 & M-3 & & M-1 & M-2 & M-3 \\
\hline 10 & 0.45 & 0.34 & 0.32 & & 91.09 & 141.14 & 216.22 \\
20 & 1.86 & 1.50 & 0.89 & & 15.06 & 26.31 & 46.00 \\
30 & 3.24 & 2.85 & 2.39 & & 5.71 & 18.00 & 20.25 \\
40 & 2.00 & 1.55 & 1.26 & & 2.07 & 8.07 & 11.00 \\
50 & 1.50 & 1.23 & 1.07 & & 0.32 & 4.97 & 5.65 \\
\hline
\end{tabular}

earlier. ${ }^{17}$ The effective membrane area in the PV cell is $32.43 \mathrm{~cm}^{2}$, and the capacity of the PV cell is about 250 $\mathrm{cm}^{3}$. The vacuum in the downstream side of the apparatus was maintained (10 Torr) by a two-stage vacuum pump (Toshniwal, Chennai, India). The test membrane was allowed to equilibrate for about $1 \mathrm{~h}$ while in contact with the feed mixture before starting the PV experiment. The PV experiments were carried out at 30,40 , and $50^{\circ} \mathrm{C}$. The traps to collect the condensed vapors were immersed in liquid nitrogen jars on the downstream side. The water composition of the feed mixture was varied between 10 and 50 mass \%. The flux was calculated by weighing permeate. The $\%$ composition of permeate was estimated by measuring refractive index of the mixture within an accuracy of \pm 0.0001 units, using a refractometer (Atago-3T, Japan). A standard plot of refractive index vs. composition of water-isopropanol mixture was established using known quantities of mixture components.

Membrane performance in PV experiments was studied by calculating the total flux $\left(J_{p}\right)$, separation factor $\left(\alpha_{\text {sep }}\right)$, and pervaporation separation index $(P S I)$. These were calculated, respectively using the following equations:

$$
\begin{gathered}
J_{p}=\frac{W_{p}}{A . t} \\
\alpha_{\text {sep }}=\frac{P_{w} / P_{I P A}}{F_{w} / F_{I P A}} \\
P S I=J_{p}\left(\alpha_{\text {sep }}-1\right)
\end{gathered}
$$

In the above equations, $W_{p}$ is the mass of permeate (g); $A$, the effective membrane area $\left(\mathrm{m}^{2}\right)$; $t$, the permeation time (h); $P$ and $F$ are mass fractions of the permeate and feed, respectively; subscripts $w$ and IPA denote water and isopropanol, respectively. Calculated values of flux and selectivity are presented in Table I.

\section{Swelling measurements}

The degree of swelling of zeolite-incorporated membranes was determined in different compositions of 
water and isopropanol mixtures for $24 \mathrm{~h}$ at $30^{\circ} \mathrm{C}$ using an electronically controlled oven (WTB Binder, Germany). The masses of the dry membranes were first determined. The dry membranes were equilibrated by soaking in different composition of the mixture in a sealed vessel, at $30^{\circ} \mathrm{C}$ for $24 \mathrm{~h}$ and then the swollen membranes were weighed immediately after careful blotting on a single pan digital microbalance (Mettler, AE240, Switzerland) having a sensitivity of \pm 0.01 $\mathrm{mg}$.The \% degree of swelling (DS) was calculated as:

$$
\operatorname{DS}(\%)=\left(\frac{W_{s}-W_{d}}{W_{d}}\right) \times 100
$$

where $W_{s}$ and $W_{d}$ are the mass of the swollen and dry membranes, respectively.

\section{Fourier transform infrared (FTIR) spectroscopy}

Dispersion of different amounts of ZSM- 5 zeolite in the PVA matrix was confirmed by FTIR (Nicolet, Impact 410, USA). Polymer samples were ground well to make $\mathrm{KBr}$ pellets under a hydraulic pressure of $600 \mathrm{~kg}$ and spectra were recorded in the range of $400-4000$ $\mathrm{cm}^{-1}$.

\section{Differential scanning calorimeter}

Thermal properties of the membranes were measured using differential scanning calorimeter (Stanton, Rederoff DSC1500) at a heating rate of $10^{\circ} \mathrm{C} / \mathrm{min}$.

\section{Wide-angle X-ray diffraction (WAXD)}

Morphologies of the PVA membranes under different loadings of zeolite were studied at room temperature using a Brucker's D-8 advanced wide-angle X-ray diffractometer. The X-ray source was Ni-filtered $\mathrm{Cu}-\mathrm{K} \alpha$ radiation $(40 \mathrm{kV}, 30 \mathrm{~mA})$. The dried membranes of uniform thickness $(\sim 40 \mu \mathrm{m})$ were mounted on a sample holder and the X-ray tracings were recorded in the range of $5-45^{\circ}$ at a speed of $8^{\circ}$ per min.

\section{RESULTS AND DISCUSSION}

\section{Membrane characterization}

\section{FTIR studies}

FTIR spectra of the crosslinked PVA membrane and those of different amounts of ZSM-5 zeolite loaded membranes are given in Figure 1. A characteristic strong and broad band appearing at around 3040 $\mathrm{cm}^{-1}$ corresponds to $\mathrm{O}-\mathrm{H}$ stretching vibrations of the hydroxyl group of PVA. On the other hand, peak intensity of the zeolite-loaded samples did not change, indicating that hydroxyl groups of PVA are not in-

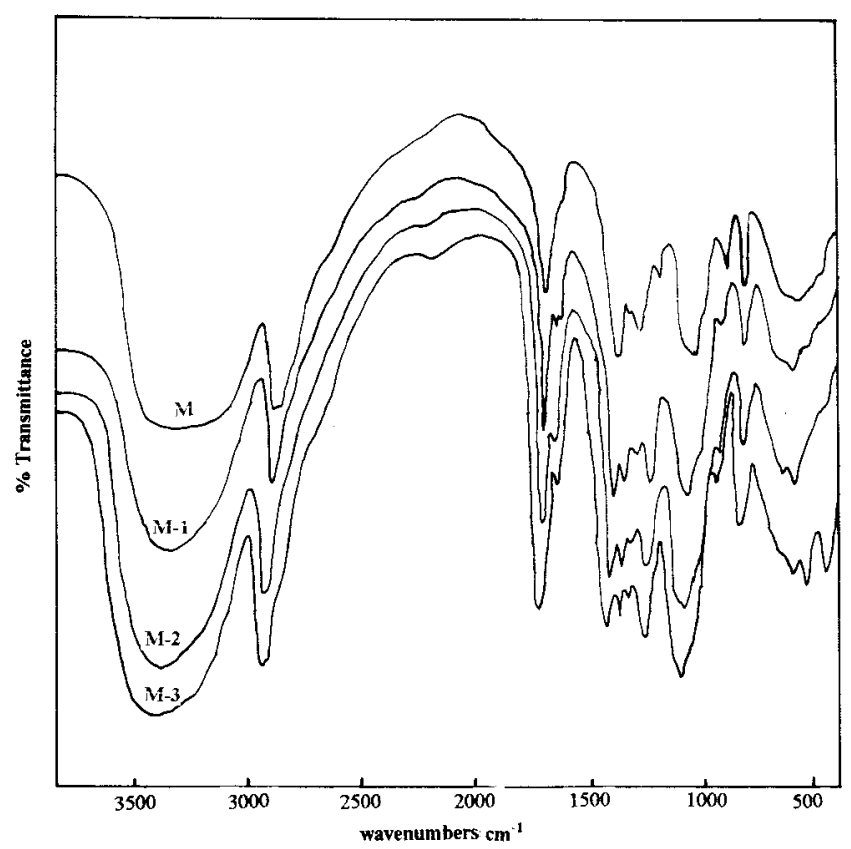

Figure 1 FTIR spectra of crosslinked PVA membranes with and without zeolite: (M) 0 mass \%; (M-1) 2 mass \%; (M-2) 4 mass \%; (M-3) 6 mass \%.

volved in any chemical reaction with the zeolites. A sharp intense band appearing at around $1100 \mathrm{~cm}^{-1}$ is assigned to $\mathrm{Si}-\mathrm{O}$ stretching, ${ }^{18}$ and the multiple bands appearing between 447 and $1000 \mathrm{~cm}^{-1}$ are assigned to the stretching of $\mathrm{Al}-\mathrm{O}$ vibrations ${ }^{19}$ due to the presence of zeolite. The intensity of these bands increased further with increasing the amount of zeolite in the membranes, which ascertains the complete dispersion of zeolite in the crosslinked PVA membranes.

X-ray diffraction studies

X-ray diffraction patterns of the membranes are presented in Figure 2. The crosslinked PVA membrane (M) exhibits a typical peak that appeared at $2 \theta=20^{\circ}$, which is almost similar to pure PVA membrane pattern ${ }^{1}$ even though the membrane was crosslinked with very small quantity of GA. A small quantity of GA did not influence on the existing state of pure PVA membrane. Thus, it can be assigned to be a mixture of (101) and (200). ${ }^{20}$ The X-ray diffraction patterns of the membranes (M-1 to M-3) show that as the loading of zeolite increased, peak intensity of the crosslinked PVA membranes decreased at around $2 \theta=20$. This revealed that the relative crystallinity of PVA crosslinked membranes decreased with increasing loading of the zeolite. An additional peak has appeared as the zeolite content was increased at around $2 \theta=23$ degree. This is due to the presence of ZSM-5 zeolite in the membranes, whose intensity further increased as the zeolite content increased in the membranes from M-1 to M-3. 


\section{Glass transition temperature $\left(T_{g}\right)$}

In an effort to study the effect of zeolite loading on the membrane morphology, the glass transitions of the different membranes were studied. Effect of zeolite loading on $T_{\mathrm{g}}$ of the crosslinked PVA membrane is shown in Figure 3. The $T_{g}$ of the crosslinked PVA membrane increased systematically with increasing the amount of zeolite, indicating that the free volume of crosslinked PVA membrane decreased with increasing the zeolite loading. This is because segmental motions of the chains are restricted by increasing the zeolite loading. Generally, an increase in free volume

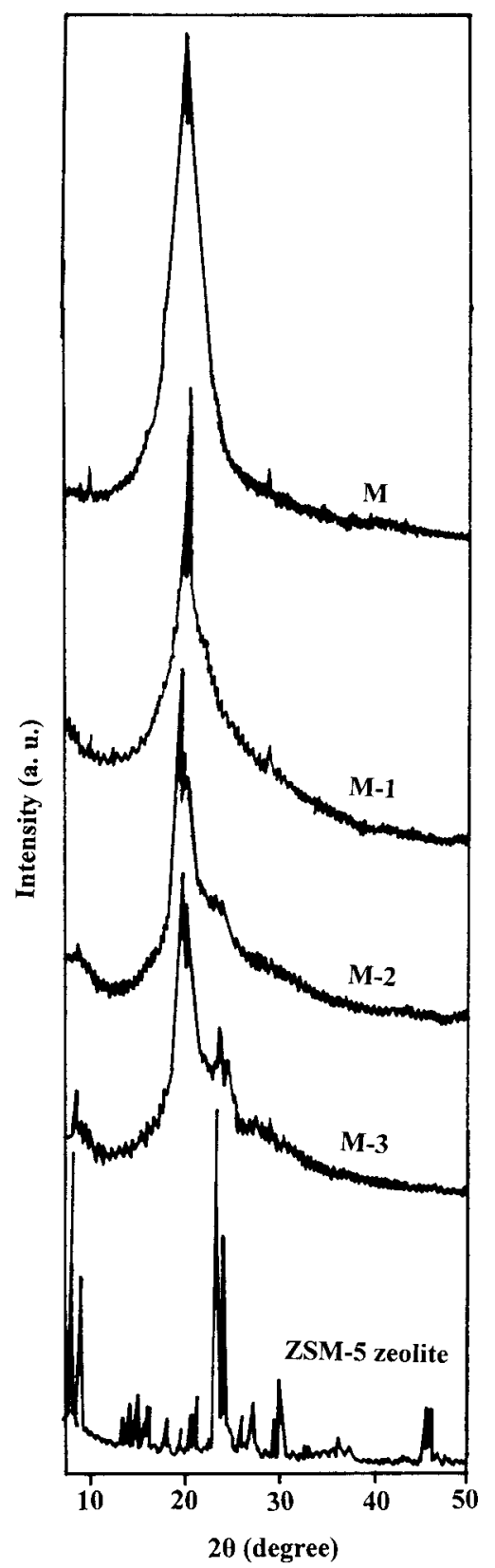

Figure 2 Wide-angle $X$-ray diffraction patterns for the membranes of crosslinked PVA (M); ZSM-5-filled PVA (M-1 to M-3); pure ZSM-5 zeolite.

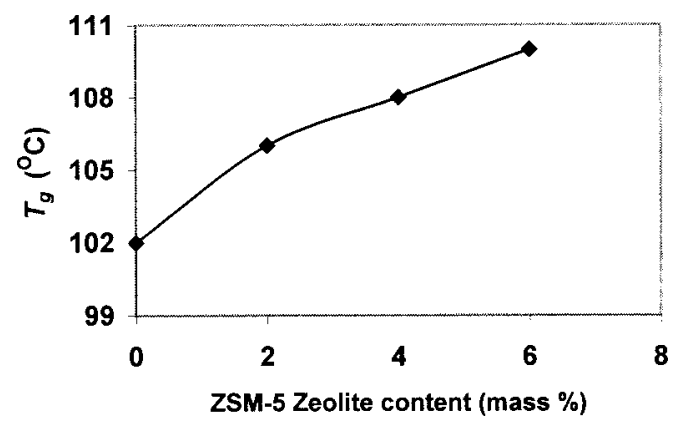

Figure 3 Effect of zeolite loading on glass transition temperatures.

leads to higher permeation flux giving a decrease in selectivity. In the present study, it is observed that upon increasing the zeolite loading, selectivity increased significantly from membranes $\mathrm{M}-1$ to $\mathrm{M}-3$, particularly the feed mixture containing 10 mass $\%$ of water (see Fig. 6), but the decrease in flux is not much significant (see Fig. 5). These observations suggest that the presence of zeolites in crosslinked PVA membranes might have increased the packing density, which in turn, is responsible for the enhancement of separation selectivity without significantly sacrificing permeation flux.

\section{Effect of feed composition on membrane swelling}

It has been realized since the pioneering work of Flory and Rehner reported in the early fifties ${ }^{21,22}$ that polymer swelling in aggressive media depends on the extent of crosslinking, morphology of the polymer, and the free volume available within the polymer matrix. In PV experiments, membrane swelling controls the transport of permeate molecules under the gradient of chemical potential. When the polymer matrices are filled with highly symmetrical zeolite particles, then it is likely that the pores of the membranes might have been occupied by the zeolite particles. Because, in the present investigation, hydrophobic property is predominant in the type of zeolite used, it hinders the chain mobility due to loss in free volume. Therefore, both solubility and diffusivity of the permeant molecules through the zeolite-filled membrane might have decreased during the PV process with increased zeolite loading.

Figure 4 shows the swelling behavior of different mass \% of zeolite-filled membranes as a function of feed mixture composition at $30^{\circ} \mathrm{C}$. It was observed that degree of swelling increased with increasing feed water concentrations up to 30 mass $\%$ and then decreased for all the membranes as the water concentrations increased beyond 30 mass \% in the feed. This unusual tendency is not only due to the free volume available in the membrane matrix but also due to the 


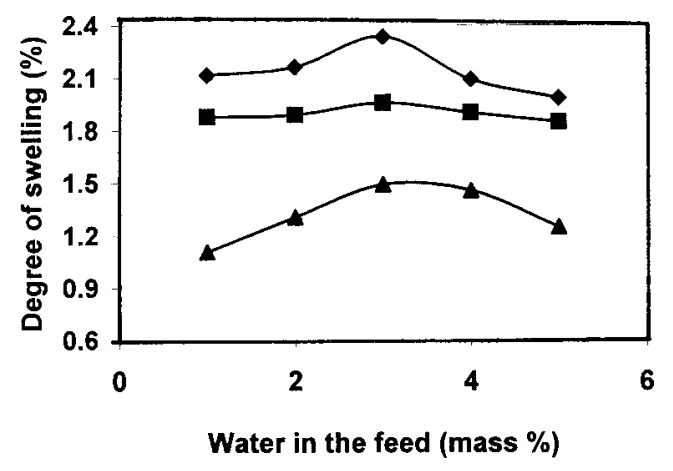

Figure 4 Variation of degree of swelling with different mass $\%$ of water in the feed for different loading of zeolite in cross-linked PVA $(\bullet) 2$ mass \% zeolite (M-1); (口) 4 mass \% zeolite (M-2); (A) 6 mass \% zeolite (M-3).

cluster formation of water molecules at higher concentrations of water in the feed.

\section{Effect of feed composition on pervaporation properties}

The effect of water composition on the total permeation flux, flux of water, and isopropanol is shown in Figure 5(A), (B), and (C). It is observed that permeation flux increased with increasing the amount of water in the feed mixture, reaching a maximum at around 30 mass \% of water, and then it decreased steeply with further increase of water composition in the feed. A similar behavior is observed for the individual components viz., water and isopropanol, as seen in Figure 5(B) and (C), respectively. Such a decreasing tendency after attaining a maximum value is due to the hindrance in permeating process occurred in the membrane owing to the formation of water clusters. At higher water contents in the feed, clustering of water molecules will be more, and cluster size might continue to increase with increasing amount of water content in the feed. ${ }^{23-25}$ On the other hand, selectivity as shown in Figure 6 decreased drastically up to 20 mass \% of water, and then it remains constant over the entire composition of water in the feed mixture, showing not much variation beyond 20 mass \% in the feed with the varying amounts of zeolite in the membranes.

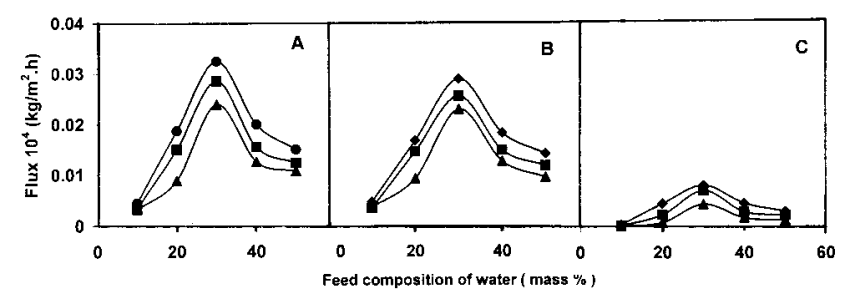

Figure 5 Variation of total flux (A), water flux (B), and IPA flux (C) with different mass \% of water in the feed. Symbols are the same as given in Figure 4.

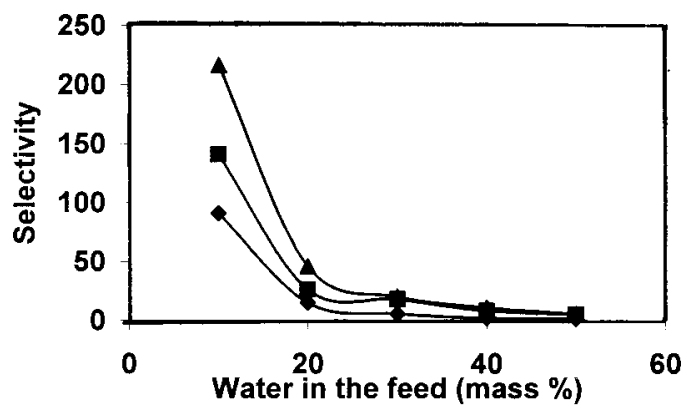

Figure 6 Variation of separation selectivity with different mass \% of water in the feed. Symbols are the same as given in Figure 4.

Calculated results of total flux and selectivity, flux of water, and isopropanol, measured at $30^{\circ} \mathrm{C}$ for different compositions of feed with respect to zeolite loading in the membranes (M-1, M-2, and M-3), are presented in Tables I and II, respectively. It is observed that there is a systematic decrease in total flux and fluxes of water and isopropanol with increasing amount of zeolite. For all the membranes, flux values of water are much higher (almost 10 times) than those obtained for isopropanol indicating the water selectivity of the membrane.

\section{Effect of zeolite loading on membrane swelling}

Figure 7 displays the effect of zeolite loading on degree of swelling for 10 mass \% of water in the feed mixture. It is found that degree of swelling decreased with increasing the amount of zeolite loading. This decrease may be due to the fact that flexibility of the polymer chains in the zeolite-filled membranes might have decreased with increasing amount of zeolite in the membrane. In addition, the hydrophilic nature of the membranes reduced from M- 1 to M-3 due to the presence of zeolite, which is hydrophobic in nature. The results of $T_{g}$ also indicated that zeolite-filled membranes have a rigid structure due to reduction in free volume upon increasing the zeolite loading.

TABLE II

Pervaporation Flux Data for Water and Isopropanol at Different Mass \% of Water in the Feed Mixture at $30^{\circ} \mathrm{C}$ for Different Membranes

\begin{tabular}{cccccccc}
\hline \multirow{2}{*}{$\begin{array}{c}\text { Mass } \% \\
\text { water }\end{array}$} & \multicolumn{3}{c}{$J_{W} 10^{2}\left(\mathrm{~kg} / \mathrm{m}^{2} \mathrm{~h}\right)$} & & \multicolumn{3}{c}{$J_{I P A} 10^{2}\left(\mathrm{~kg} / \mathrm{m}^{2} \mathrm{~h}\right)$} \\
\cline { 3 - 4 } \cline { 7 - 8 } & $\mathrm{M}-1$ & $\mathrm{M}-2$ & $\mathrm{M}-3$ & & $\mathrm{M}-1$ & $\mathrm{M}-2$ & $\mathrm{M}-3$ \\
\hline 10 & 0.41 & 0.30 & 0.31 & & 0.04 & 0.02 & 0.01 \\
20 & 1.47 & 1.28 & 0.82 & & 0.39 & 0.20 & 0.07 \\
30 & 2.54 & 2.24 & 2.01 & & 0.70 & 0.61 & 0.38 \\
40 & 1.60 & 1.30 & 1.11 & & 0.40 & 0.25 & 0.15 \\
50 & 1.24 & 1.03 & 0.83 & & 0.26 & 0.20 & 0.11 \\
\hline
\end{tabular}




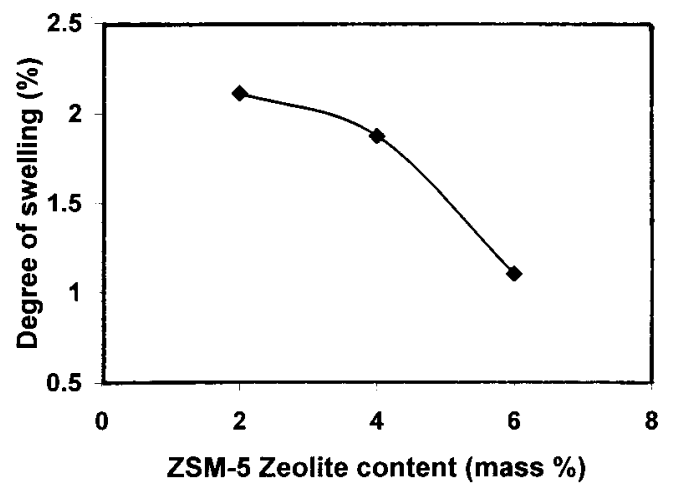

Figure 7 Variation of degree of swelling with different mass \% of zeolite at 90 mass \% of IPA in the feed.

\section{Effect of zeolite loading on pervaporation properties}

The PV performance of the membranes for the feed mixture containing 10 mass \% of water is shown in Figure 8, indicating that water selectivity increased almost linearly with increasing the amount of zeolite due to the reduction in free volume of the membrane matrix. On the contrary, the decrease in flux is not too significant when compared to selectivity from membranes M-1 to M-3. This is probably due to the presence of the ZSM-5 zeolite, which has the elliptical and sinusoidal channels with an opening of $0.51 \times 0.57 \mathrm{~nm}$ and a diameter of $0.54 \mathrm{~nm}$, respectively, facilitating the water transport to some extent, even though there is a reduction in free volume as the amount of zeolite increased.

\section{Effect of zeolite loading on pervaporation separation index}

The pervaporation separation index (PSI), which is the product of total permeation rate and selectivity, characterizes the performance of PV membranes. Figure 9 displays the dependence of PSI as a function of amount of the zeolite in the membranes. It is found that the PSI values increased as the loading of zeolite increased, indicating that the membranes of the

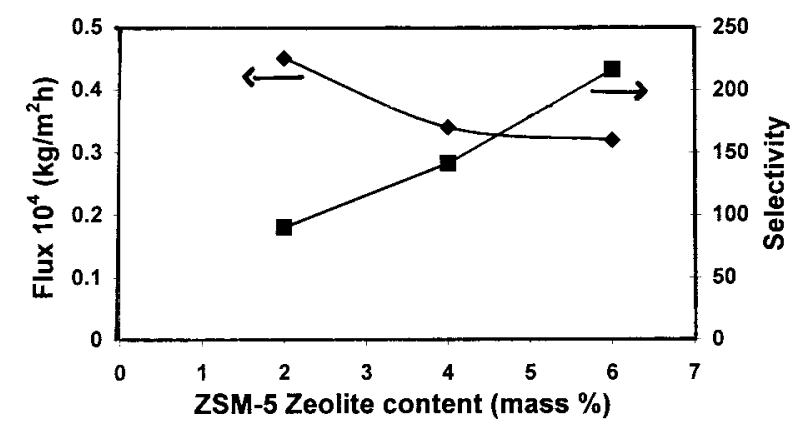

Figure 8 Variation of flux and selectivity with different mass \% of zeolite at 90 mass \% of IPA in the feed.

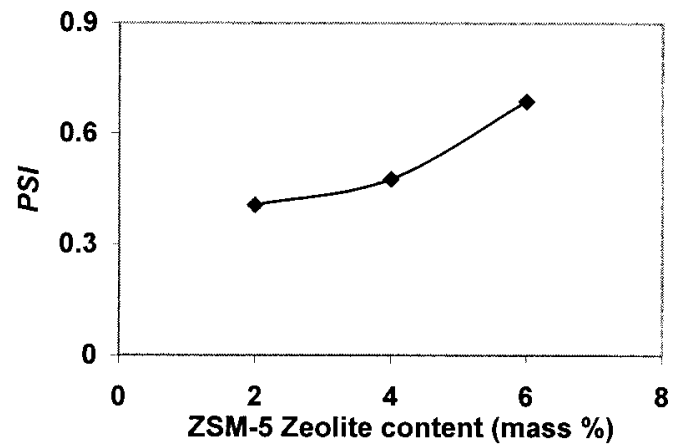

Figure 9 Variation of permeation separation index with different mass \% of zeolite at 90 mass \% of IPA in the feed.

present study showed better performance at higher loading of zeolite.

\section{Effect of temperature}

The effect of temperature on PV performance of the water-isopropanol mixture for zeolite-filled membranes has been studied for the feed mixture containing 10 mass \% of water. The results of PV flux and separation selectivity data at 30,40 , and $50^{\circ} \mathrm{C}$ are presented in Table III. It is observed that the flux values increased systematically with increasing temperature, whereas separation selectivity values decreased with increasing temperature. This is due to the expansion of free volume in the polymer matrix and plasticizing effect of water molecules in the membranes at higher temperature. However, at lower temperature, only water molecules can transport through the membrane matrices. The flux decreases and selectivity increases from membrane M-1 to M- 3 at all the temperatures, thereby exhibiting the effect of temperature.

The temperature dependency of permeation flux was therefore studied by using Arrhenius relationship

$$
J p=J p_{o} \exp \left(\frac{-E_{p}}{R T}\right)
$$

Here, $J p_{o}$, and $E_{p}$ are, respectively, the preexponential factor and activation energy for permeation; $R$ is gas constant, and $T$ is temperature in Kelvin. If acti-

TABLE III

Pervaporation Flux and Separation Selectivity at Different Temperatures for 10 Mass \% of Water in the Feed Mixture for Different Membranes

\begin{tabular}{|c|c|c|c|c|c|c|}
\hline \multirow{2}{*}{$\begin{array}{l}\text { Temperature } \\
\left({ }^{\circ} \mathrm{C}\right)\end{array}$} & \multicolumn{3}{|c|}{$J p 10^{2}\left(\mathrm{~kg} / \mathrm{m}^{2} \mathrm{~h}\right)$} & \multicolumn{3}{|c|}{$\alpha_{\text {sep }}$} \\
\hline & M-1 & M-2 & M-3 & M-1 & M-2 & M-3 \\
\hline 30 & 0.45 & 0.34 & 0.32 & 91.09 & 141.14 & 216.22 \\
\hline 40 & 0.88 & 0.76 & 0.56 & 55.34 & 59.46 & 119.69 \\
\hline 50 & 1.20 & 1.11 & 1.00 & 33.04 & 51.05 & 66.07 \\
\hline
\end{tabular}


TABLE IV

Diffusion Coefficients of Water and Isopropanol Calculated $^{6}$ at Different Temperatures for 10 Mass \% of Water in the Feed Mixture for Different Membranes

\begin{tabular}{llllllll}
\hline \multirow{2}{*}{$\begin{array}{c}\text { Temperature } \\
\left({ }^{\circ} \mathrm{C}\right)\end{array}$} & \multicolumn{3}{c}{$D_{w} 10^{6}\left(\mathrm{~cm}^{2} / \mathrm{s}\right)$} & & \multicolumn{3}{c}{$D_{I P A} 10^{6}\left(\mathrm{~cm}^{2} / \mathrm{s}\right)$} \\
\cline { 2 - 3 } & $\mathrm{M}-1$ & $\mathrm{M}-2$ & $\mathrm{M}-3$ & & $\mathrm{M}-1$ & $\mathrm{M}-2$ & $\mathrm{M}-3$ \\
\hline 30 & 0.709 & 0.500 & 0.505 & & 0.069 & 1.667 & 1.628 \\
40 & 1.400 & 1.200 & 0.877 & & 0.022 & 0.182 & 0.067 \\
50 & 1.903 & 1.755 & 1.580 & & 0.025 & 0.298 & 0.215 \\
\hline
\end{tabular}

vation energy is positive, then permeation flux increases with increasing the temperature, and this is indeed the case in most of the PV experiments. ${ }^{26,27}$ The driving force for mass transport also increases with increasing the temperature. As the feed temperature increases, vapor pressure in the feed compartment also increases, but vapor pressure at the permeate side is not affected. These result in an increase of driving force due to increase in temperature. In a similar way, mass transport due to diffusion was calculated using Arrhenius equation,

$$
D_{i}=D_{i o} \exp \left(\frac{-E_{D}}{R T}\right)
$$

Here, $E_{D}$ is the energy of activation for diffusion, and $i$ stands for water or isopropanol components of the mixture. The least square estimations of $E_{D}$ values are calculated using the values given in Table IV.

Arrhenius plots of $\log J_{p}$ vs. $1 / T$ and $\log D_{i}$ vs. $1 / T$ are shown in Figures 10 and 11(A) and (B) for temperature dependence of total permeation and diffusion, respectively. In all the cases, linear behavior is observed, signifying that temperature dependence of total permeation flux or diffusivity follows the Arrhenius trend. The apparent activation energy values $\left(E_{p}\right.$ and $E_{D}$ for permeation and diffusion, respectively) calculated from the slopes of the straight lines of the Arrhenius plots by the least squares method and the

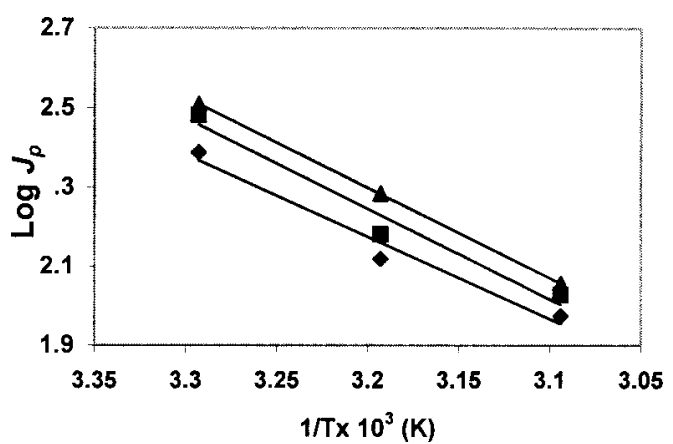

Figure 10 Variation of $\log J p$ with temperature at 90 mass $\%$ of IPA in the feed. Symbols are the same as given in Figure 4.

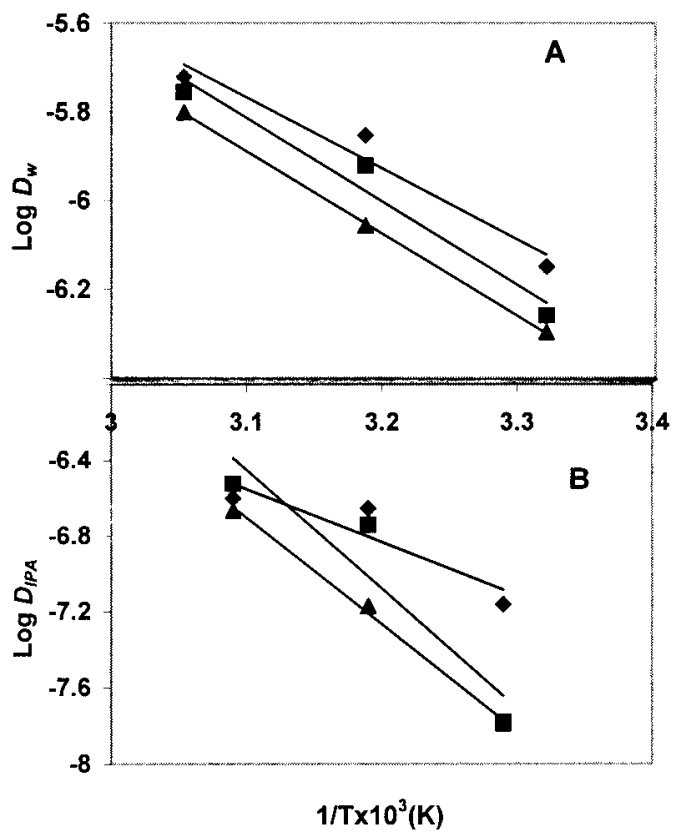

Figure 11 Variation of $\log D_{w}(\mathrm{~A})$ and $\log D_{I P A}(\mathrm{~B})$ with temperature at 90 mass $\%$ of IPA in the feed. Symbols are the same as given in Figure 4.

heat of sorption $\left(\Delta H_{s}=E_{p}-E_{D}\right)$ are presented in Table V. The $E_{p}$ values ranged between -38.79 and $-42.77 \mathrm{~kJ} / \mathrm{mol}$. However, the $E_{p}$ values do not show any systematic variation with the amount of zeolite in the membranes. The $\Delta H_{s}$ values are negative in all the cases, suggesting an exothermic mode of sorption.

The temperature dependence of $\alpha_{\text {sep }}$ was further studied by employing the relationship proposed by Ping et al. ${ }^{28}$

$$
Y w=\frac{1}{1+\left(J_{I P A} / J_{w}\right) \exp \left(-E_{I P A}+E_{w}\right) / R T}
$$

where $Y_{w}$ is water composition in the permeate; $J_{w}$ and $J_{I P A}$ are the permeating flux of water and isopropanol, respectively; $E_{w}$ and $E_{I P A}$ are the Arrhenius activation energies for diffusion of water and isopropanol, respectively, at the average energy level. The positive value of $\left(E_{I P A}-E_{w}\right)$ indicates that $\alpha_{\text {sep }}$ decreases with an increase in temperature. ${ }^{29}$ In the present study, calculated values are positive for all the membranes

TABLE V

Arrhenius Activation Parameters for Permeation, Diffusion, and Heat of Sorption and Energy Difference Values for Water

\begin{tabular}{lrrr}
\hline \multicolumn{1}{c}{ Parameters } & \multicolumn{1}{c}{ M-1 } & \multicolumn{1}{c}{ M-2 } & \multicolumn{1}{c}{ M-3 } \\
\hline$E_{p}$ (kJ/mol) eq. (5) & -38.79 & -42.77 & -42.47 \\
$E_{D}$ (kJ/mol) eq. (6) & 40.37 & 47.41 & 46.44 \\
$\Delta H_{s}(\mathrm{~kJ} / \mathrm{mol})$ & -79.16 & -90.17 & -88.91 \\
$E_{I P A}-E_{w}(\mathrm{~kJ} / \mathrm{mol})$ & 90.20 & 154.40 & 143.76 \\
\hline
\end{tabular}


(see Table V), indicating that $\alpha_{\text {sep }}$ decreases with increasing temperature.

\section{CONCLUSIONS}

Incorporation of ZSM-5 zeolite in PVA has shown an improvement in the membrane performance while separating water-isopropanol mixtures. Selectivity increased significantly from membranes M-1 to M-3 due to a reduction in free volume as well as packing density with increasing zeolite content. However, selectivity decreased drastically up to 20 mass \% of water in the feed and remained almost constant when the water concentration increased beyond 20 mass \%, signifying that separation selectivity is much influenced at lower composition of water in the feed. Highest separation selectivity is found to be 216 for 6 mass \% zeolite loading in the membrane at $30^{\circ} \mathrm{C}$ without sacrificing permeation flux significantly. The PV separation index data also indicated that higher the degree of zeolite loading better is the membrane performance. On the other hand, permeation flux and swelling behavior increased with increasing the amount of water up to 30 mass \% in the feed and then, decreased with increasing water composition. This was explained on the basis of the cluster formation of water molecules. Molecular transport in the present system not only depends upon, morphology of the polymer and free volume of the polymer matrix, but also depends on the cluster formation of water molecules as well as zeolite loading. With regard to temperature effects, permeation flux increased, but selectivity decreased when the temperature increased, suggesting that ZSM-5-filled PVA membranes are good for the dehydration of isopropanol.

\section{References}

1. Nam, S. Y.; Chun, H. J.; Lee, Y. M. J Appl Polym Sci 1999, 72, 241.
2. Tusel, G. F.; Bruschke, H. E. A. Desalination 1985, 53, 327.

3. Flemming, H. L. Chem Eng Prog 1992, 88, 45.

4. Brano, J. L.; Fair, J. R.; Humphrey, J. L.; Martio, C. L.; Seibert, A. F.; Joshi, S. Fluid Mixtures Separation Technologies for Cost Reduction and Process Improvement; Noyes: Park Ridge, NJ, 1986.

5. Neel, J.; Nguyen, Q. T.; Clement, R.; Blane, L.; Le Blank, L. J Membr Sci 1983, 15, 43.

6. Kurkuri, M. D.;Toti, U. S.; Aminabhavi, T. M. J Appl Polym Sci 2002, 86, 3642.

7. Kim, K. J.; Park, S. H.; So, W. W.; Moon, S. J. J Appl Polym Sci 2000, 79, 1450.

8. te Hennepe, H. J. C.; Bargeman, D.; Mulder, M. H. V.; Smolders C. A. J Membr Sci 1987, 35, 39.

9. Jia, M. D; Peinemann, K. V.; Behling, R. D. J Membr Sci 1991, 57, 297.

10. Dotremont, C.; Goethaert, S.; Vandecasteele, C. Desalination 1993, 91, 177.

11. Vankelecom, I. F. J.; Depre, D.; De Beuckelaer, S.; Uytterhoven, J. B. J Phys Chem 1995, 99, 13193.

12. Tuan, V. A.; Li, S.; Falconer, J. L.; Noble, R. D. J Membr Sci 2002, 196, 111.

13. Dong, W. Y.; Long, Y. C. Chem Commun 2000, 1067.

14. Vroon, Z. A. E. P.; Keizer, K.; Burggraaf, A. J.; Verweij, H. J Membr Sci 1998, 144, 65.

15. Komarneni, S.; Katsuki, H.; Furuta, S. Mater Chem 1998, 8, 2327.

16. Flanigen, E. M.; Bennett, J. M.; Grose, R. W.; Cohen; J. P.; Patton, R. L; Kirchner, R. M. Nature 1978, 271, 512.

17. Aminabhavi, T. M.; Naik, H. G. J Appl Polym Sci 2002, 83, 244.

18. Bellamy, N. J. The Infra-red Spectra of Complex Molecules; Chapman and Hall Ltd: London, 1975, p. 378.

19. Mitra, N. K. Dana, K.; Basumujumdar, A. J Indian Chem Soc 2002, 79, 916.

20. Nishino, Y.; St. Johnmanley, R. Macromolecules 1988, 21, 1270.

21. Flory, P. J. Principles of Polymer Chemistry; Cornell University Press: Ithaca, NY, 1953.

22. Flory, P. J.; Rehner, J., Jr. J Chem Phys 1943,11,521.

23. Yasuda, H.; Stannett, V. J Polym Sci 1962, 57, 907.

24. Wellons, J. D.; Stannett, V. J Polym Sci 1966, 4, 593.

25. Huang, R. Y. M; Jarvis, N. R. J Appl Polym Sci 1970, 14, 2341.

26. Burshe, M. C.; Netke, S. A.; Sawant, S. B.; Joshi, J. B.; Pangarkar, V. G. Sep Sci Technol 1997, 32, 1335.

27. Nam, S. Y.; Lee, Y. M. J Membr Sci 1999, 157, 63.

28. Ping, Z. H.; Nguyen, Q. T.; Clement, R.; Neel, J. J Membr Sci 1990, 48, 297.

29. Binning, R. C.; Lee, R. J.; Jennings, J. F.; Martin, E. C. Ind Eng Chem 1961, 53, 45. 